\title{
Knowledge and Confidence Level Among Emergency Healthcare Workers in Airway Management and Resuscitation of Suspected COVID-19 Patients: A Cross Sectional Study in Malaysia
}

\author{
Azlan Helmy Abd Samat, ${ }^{1}$ Dr Em Med, Mohd Hisham Isa, ${ }^{1}$ Dr Em Med, Dazlin Masdiana Sabardin, ${ }^{1}$ MEmMed,
} Shamsuriani Md Jamal, ${ }^{1}$ MEmMed, Mohd Johar Jaafar, ${ }^{1}$ MSurg (Orth and Truuma), Faizal Amri Hamzah, ${ }^{1}$ MMed (EM), Alias $\underline{\text { Mahmud, }}{ }^{1}$ PhD, Amirudin $\underline{\text { Sanip }},{ }^{1}$ MD, Syed Mohammad Syed Ali, ${ }^{1}$ MD, Ismail Mohd Saiboon, ${ }^{1}$ MSurg (Orth and Trauma)

\begin{abstract}
Introduction: This study aims to evaluate the knowledge and confidence of emergency healthcare workers (EHCW) in facing the COVID-19 pandemic. Materials and Methods: A cross-sectional online study using a validated questionnaire was distributed to doctors (MD), assistant medical officers (AMO), and staff nurses (SN) at an urban tertiary Emergency Department. It comprised of 40 knowledge and 10 confidence-level questions related to resuscitation and airway management steps. Results: A total of 135 from 167 eligible EHCW were enrolled. $68.9 \%$ (n $=93)$ had high knowledge while $53.3 \%(n=72)$ possessed high confidence level. Overall knowledge mean score was $32.96 / 40(\mathrm{SD}=3.63)$ between $\mathrm{MD}(33.88 \pm 3.09)$, AMO (32.28 \pm 4.03$)$, and $\mathrm{SN}(32.00 \pm 3.60), P=0.025$. EHCWs with a length of service (LOS) between 4-10 years had the highest knowledge compared to those with LOS $<4$-year $(33.71 \pm 3.39$ versus $31.21 \pm 3.19 P=\mathbf{0 . 0 0 2})$. Airway-related knowledge was significantly different between the designations and $\operatorname{LOS}(P=0.002$ and $\boldsymbol{P}=\mathbf{0 . 0 0 3}$, respectively). Overall, EHCW confidence level against LOS showed significant difference $[\mathrm{F}(2,132)=5.46, P=0.005]$ with longer LOS showing better confidence. MD showed the highest confidence compared to AMO and SN $(3.67 \pm 0.69,3.53 \pm 0.68$, 3.26 \pm 0.64$) ~ P=\mathbf{0 . 0 4 9}$. The majority $\mathrm{EHCW}$ were confident in performing highquality chest-compression, and handling of Personal Protective Equipment but less than half were confident in resuscitating, leading the resuscitation, managing the airway or being successful in first intubation attempt. Conclusions: EHCW possessed good knowledge in airway and resuscitation of COVID-19 patients, but differed between designations and LOS. A longer LOS was associated with better confidence, but there were some aspects in airway management and resuscitation that needed improvement.
\end{abstract}

Ann Acad Med Singap. 2020;49:643-51

Key words: Airway; Confidence; COVID-19; Knowledge; Resuscitation (CPR).

\section{Introduction}

The World Health Organization (WHO) has declared the severe acute respiratory syndrome coronavirus 2 disease (also known as COVID-19) a pandemic on 11 March 2020. Since then, COVID-19 has spread to more than 200 countries globally ${ }^{1}$ and the mortality rate ranges from 1 to $20 \%$ depending on the country. ${ }^{2,3}$ Many countries were caught off guard when this disease struck. In fact, from the day of the fifth confirmed death, the country with the highest COVID-19 mortality had shifted from Wuhan, China to Europe, then to the United States of America and subsequently, to South
America. ${ }^{4}$ Furthermore, at the time this article was written in early August, 2020, there were more than 18 million confirmed cases with more than 680000 deaths reported worldwide from January 2020. ${ }^{1,4}$

In the early stages of the disease, infected patients show symptoms that are indistinguishable from upper respiratory tract infection (URTI). It then progresses to more severe and critical conditions such as severe breathlessness, high grade fever, haemodynamic instability or circulatory collapse..$^{5-7}$ Like any other collapsed patient, suspected COVID-19 patients require cardiopulmonary resuscitation (CPR) with airway management, but

${ }^{1}$ Department of Emergency Medicine, Faculty of Medicine, Universiti Kebangsaan Malaysia, Malaysia

Address for Correspondence: Prof Dr Ismail Mohd Saiboon, Department of Emergency Medicine, Faculty of Medicine, University Kebangsaan Malaysia, Jalan Yaacob Latif, Bandar Tun Razak, Cheras, 56000 Kuala Lumpur, Malaysia

Email: ismail@ppukm.ukm.edu.my 
with special precautionary measures, which need to be understood and taken by the resuscitation team. ${ }^{8,9}$ Emergency health care workers (EHCW) need special training to approach suspected COVID-19 cases because of the high risks of transmission from patients and spread among themselves. ${ }^{10}$ Within a short period of time, EHCW ought to learn new knowledge, adapt to new policies and guidelines, and overcome their fears and anxieties while maintaining professionalism in delivering emergency care services. ${ }^{11} \mathrm{~A}$ cross sectional study in Pakistan among $\mathrm{HCW}$ revealed positive findings on knowledge and attitude towards COVID-19. ${ }^{12}$ However, this study did not focus on $\mathrm{EHCW}$ as it involved doctors, nurses and pharmacists in general. In addition, confidence in airway management and resuscitation was not explicitly explored. ${ }^{12}$ Meanwhile, a study in Wuhan, China involving the frontline HCWs including doctors, nurses and paramedics showed good correlation between knowledge, confidence level and attitudes in handling COVID-19 cases. $^{13}$

In Malaysia, the threat of COVID-19 became apparent when Singapore reported its first imported COVID-19 case from Wuhan, China on 23 January 2020 , followed by identification of close contacts of the case in Johor, Malaysia. ${ }^{6,14}$ Less than 2 days after the first case was reported in Singapore, Malaysia reported its first COVID-19-positive case on 25 January 2020; an imported case from Wuhan, China. ${ }^{15}$ The situation became worse in Malaysia in March after the International Health Regulations (IHR) Malaysia received information on one positive case in Brunei. The patient had attended a mass religious gathering in Seri Petaling Mosque, Selangor, Malaysia, from 27 February to 1 March 2020, which was attended by more than 10,000 participants from numerous countries, with the majority coming from Malaysia. ${ }^{16} \mathrm{At}$ the time this article was written, the country has recorded more than 9,000 confirmed cases, with a mortality rate of around $1.4 \%$ (125 deaths).${ }^{17}$ All hospitals' HCW were alerted to the potential influx of high-risk patients throughout the country.

We set out to determine the readiness of EHCW in terms of knowledge and confidence level in dealing with this deadly disease. This is crucial as only with good level of preparedness and sufficient knowledge will the EHCW be able to face this situation confidently and with a high degree of safety. ${ }^{9}$ Furthermore, specialised training should be introduced to train all in mitigating this problem. ${ }^{9}$

\section{Methodology}

This is a cross-sectional study to investigate the knowledge and confidence level of EHCW working in the Emergency Department (ED) of a tertiary teaching hospital located in Kuala Lumpur. The EHCW were categorised into 3 designations: medical doctors (MD), assistant medical officers (AMO) and staff nurses (SN). It was conducted from 1 April 2020 to 31 May 2020. During this period, the government enforced strict lockdown measures aimed at containing the spread of the disease. The inclusion criterion was all EHCW who were active for duty during the study period. We excluded those who declined to participate in the study.

This study collected data using an online selfadministered questionnaire that can be obtained through the link https://forms.gle/jVi46LkZfAQuuEb78 (Figure 1). The questionnaire was designed on a Google form and its link was shared with all the emergency department healthcare workers via a dedicated WhatsApp group (Whatsapp Messenger Version 2.20.193.9. Whatsapp Inc. Boston, MA). The link was also shared directly with individual $\mathrm{EHCW}$ who were in the contact lists of the investigators or via e-mail communication.

A survey instrument was designed based on guidelines, reports, course materials on resuscitation and respiratory disease including COVID-19., ${ }^{8,18-20}$ The questionnaire was divided into two parts. Part A was related to the demography of the respondents, comprising age, gender, EHCW designation categories and length of service (LOS) which was defined as the number of years of working as a healthcare provider.

Part B consisted of 40 questions that were related to knowledge, and 10 questions related to confidence level, respectively. Among the knowledge-related questions, 23 were about airway management and the other 17 were about resuscitation measures. These questions required the respondents to select the answer in each statement to be either true or false.

The 10 questions related to confidence level consisted of 4 questions on airway-related confidence (ARC) (Q2, Q3, Q7, Q9), 4 questions on resuscitation-related confidence (RRC) (Q1, Q4, Q5, Q10), and the remaining 2 questions were on personal protective equipment (PPE) (Q6, Q8).

The respondents indicated their answers based on a 5 -point Likert scale; strongly agree $=5$; agree $=4$; undetermined $=3$; disagree $=2$; and strongly disagree $=$ 1. The questionnaire was validated by 3 local emergency physicians and a pilot study was conducted to obtain the reliability of this questionnaire. Cronbach alpha $(\alpha)$ score for the questionnaire was 0.748 .

The sample size calculated by Krejcie and Morgan formula was 118 , assuming a response rate of $50 \%$, 
Fig. 1. Questionnaire

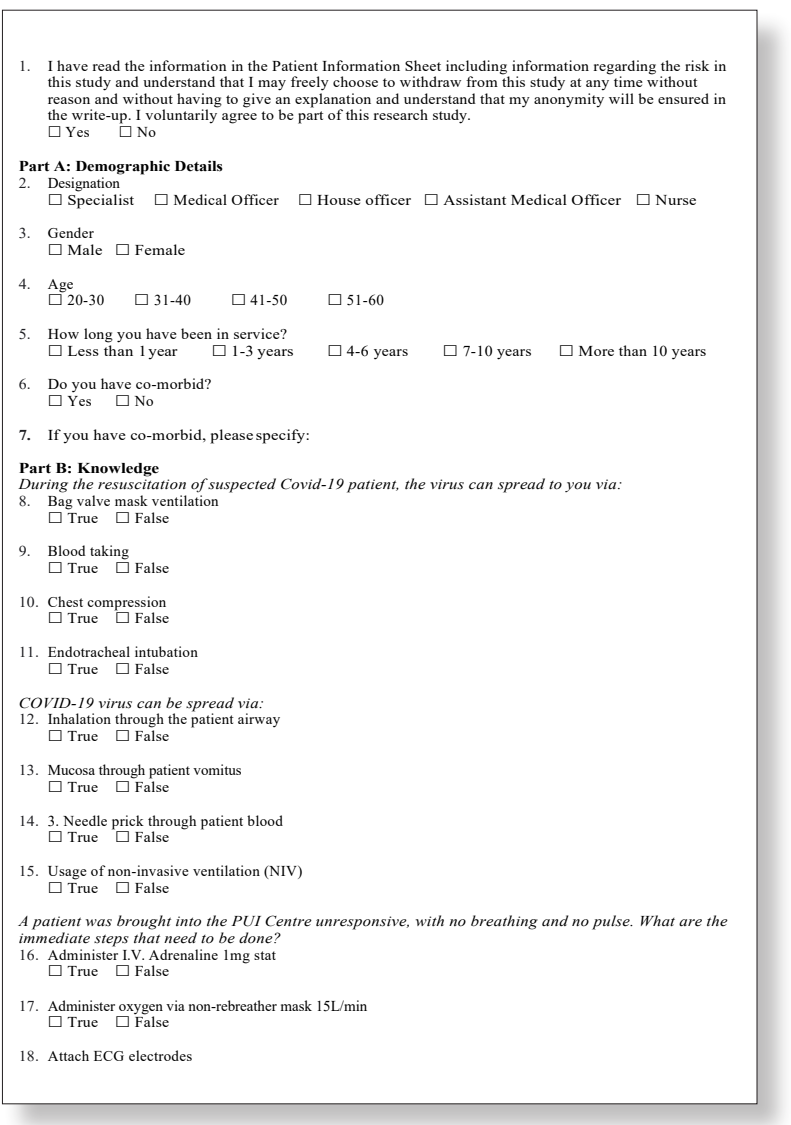

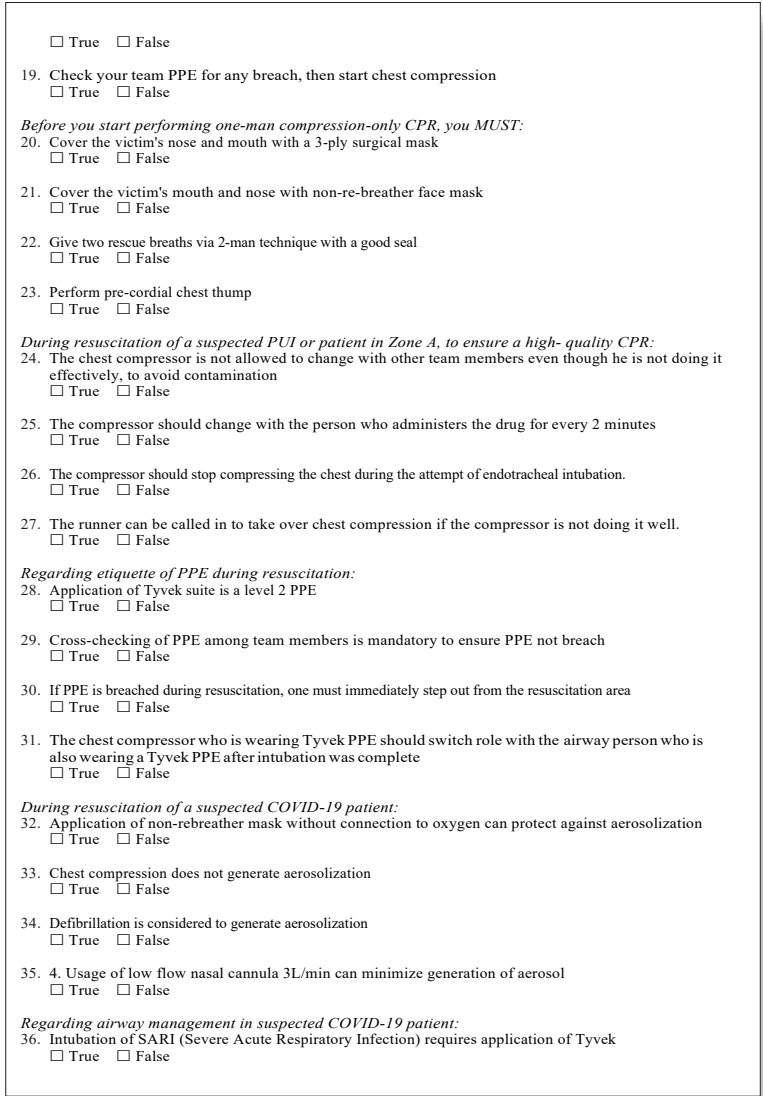

37. Minimum of 4 people are required to attend to intubation of SARI patientin the emergency department

38. Pre-oxygenation with $15 \mathrm{~L} / \mathrm{min}$ high flow mask oxygen is recommended
$\square$ True $\square$ False

39. Suctioning of the airway prior to intubation increases risk of aerosolization
$\square$ True $\square$ False

Regarding intubation of suspected COVID-19 patient:
40 . Wearing a face shield does not improve safety unless the intubator also wears N95 mask 41. During intubation of a suspected COVID-19 case, an adequate dose of muscle relaxant must be given
in order to achieve total paralysis

42. If there is a failure of intubation with the conventional approach, the intubating personnel should resort to cricothyroidotomy immediately
$\square$ True $\square$ False

43. Risk of aerosolization increases during a change of tubing of ventilator
$\square$ True $\square$ False

Regarding intensive care management of a suspected Covid-19 patient:
44. End-tidal CO2 capnography is NOT recommended in determining the correct placement of ETT

45. Intubated SARI patient can be managed in normal Non-Covid General ICU
$\square$ True $\square$ False

46. Suctioning of the patient's oral pharyngeal with Yankauer suction is permissible
$\square$ True $\square$ False

47. The ventilator tubing should be sealed at all connection points
$\square$ True $\square$ False

Part C: Confidence
On a scale of $1-5$, with 1 being strongly disagree, 2 is disagree, 3 is indeterminate, 4 is agree and 5 being On a cale of $1-5$, with 1 being strongly disagree, 2 is disagree, 3 is indeterminate, 4 is agree and 5 being
strongly agree, How would you rate your confidence level on resuscitation of PUI/COVID positive patient
during the COVID-19 pandemic?

48. You are comfortable resuscitating a PUI patient
$\square 1$$\square 2 \quad \square 3 \quad \square 4 \quad \square 5$

49. You are well trained to manage the airway

50. You are confident in managing the airway
$\square 1$
$\square$

51. You are comfortable in doing High-Quality CPR on the patient

52. You are comfortable to lead the resuscitation team

53. You are comfortable checking your PPE for any breach

54. You are comfortable in voicing your concern to your senior if the need arises
$\square 1 \quad \square 2 \quad \square 3 \quad \square 4 \quad \square 5$

55. You are confident of achieving success on your 1st intubation attempt

56. You know what to do if you notice your PPE is breached during resuscitation
$\square 1 \quad \square 2 \quad \square 3 \quad \square 4 \quad \square 5$ 57. You know what to do if the patient suddenly vomits on you during intubation attempt 
95\% confidence interval (CI), Z of 1.96 and margin of error of $5 \%$. A further $10 \%$ was added to counteract any errors in completing the questionnaire, resulting in a final sample size of 130 .

The results were analysed descriptively for the number of respondents, percentage, and the mean for overall and each category of designation and LOS using SPSS version 26 (IBM Corp, Armonk, NY). We analysed the mean knowledge score and confidence level for each category of EHCW based on the different designation and LOS using one-way ANOVA and Post Hoc Tukey HSD. Further analyses were done on the confidence level of the three-separate cluster of airway, resuscitation and PPE. Chi squared test and Pearson's rank correlation were used to compare differences in knowledge and confidence level of EHCW by demographic characteristics.

This study complied with, and received the approval from, the Medical Research Ethics Committee (MREC), Universiti Kebangsaan Malaysia (approval no. FF2020-185). In addition, the confidentiality of all the respondents was guaranteed, and all respondents agreed to participate in the study voluntarily by signing the consent form before answering the questionnaire.

\section{Results}

Out of the 167 total EHCW eligible for the study, 135 responded to the questionnaire and were included in the final analysis. These respondents consisted of: MD 45.9\% $(\mathrm{n}=62)$, AMO 37.8\% $(\mathrm{n}=51)$ and SN $16.3 \%$ $(\mathrm{n}=22)$. Of these, $51.9 \%(\mathrm{n}=70)$ were males, and $68.2 \%$ were aged between 31 and 40 years. In terms of working experience, $83.0 \%(\mathrm{n}=112)$ had less than 10 years of experience. Only $11.9 \%(n=16)$ of them had comorbid illnesses. Table 1 shows details of the demography.

\section{Knowledge of EHCW on Managing COVID-19}

Overall, this study revealed that $68.9 \%(\mathrm{n}=93)$ of EHCW had good knowledge, and 53.3\% ( $\mathrm{n}=72)$ had high confidence level in resuscitation and airway management of suspected COVID-19 patients (Table 1). Table 2 displays the mean scores of knowledge among different designations and LOS. Out of total score of 40 , the mean score for overall knowledge was 32.96 $(\mathrm{SD}=3.63)$. One-way ANOVA showed significant difference of knowledge scores between the different designations and LOS with $P=0.025$ and 0.004 , respectively. Post hoc analyses revealed a significant difference between MD $(\mathrm{M}=33.88, \mathrm{SD}=3.09)$ and AMO $(\mathrm{M}=32.28, \mathrm{SD}=4.03)$ with $P=0.049$. In terms of LOS, the overall knowledge level for 4-10 years $(\mathrm{M}=33.71, \mathrm{SD}=3.39)$ was significantly higher than $\operatorname{LOS}<4$ years $(\mathrm{M}=31.21, \mathrm{SD}=3.19)$, with $P=0.002$. However, there was no statistically significant difference between LOS duration 4-10 years and $>10$ years of service.

Subsequent analyses of the 23 questions on airway related knowledge (ARK) using one-way ANOVA revealed significant difference between designations with $P=0.002$. Post hoc Tukey HSD test indicated significant difference between $\mathrm{MD}$ and $\mathrm{SN}(\mathrm{M}=20.67$, $\mathrm{SD}=1.99$ versus $\mathrm{M}=18.68, \mathrm{SD}=2.70$ ) with $P=0.002$. An analysis based on different LOS showed statistically significant difference $(\mathrm{F}(2,132)=6.262, P=0.003)$. Post hoc comparison showed that the ARK for LOS $<4$ years $(\mathrm{M}=18.82, \mathrm{SD}=2.35)$ was significantly lower than LOS 4-10 years $(\mathrm{M}=20.50, \mathrm{SD}=2.32)$ with $P=0.002$.

Analyses of the 17 questions on Resuscitation Related knowledge (RRK) using one-way ANOVA revealed no significant difference between designation and LOS with $[\mathrm{F}(2,132)=1.59, P=0.207]$ and $[\mathrm{F}(2,132)=2.017$, $P=0.137]$, respectively (Table 2 ).

\section{Confidence Level with Designation and Length of Service}

Table 3 displays the mean confidence scores among different designations and LOS. There was a significant difference in overall confidence level among the different designations, based on one-way ANOVA test, $[\mathrm{F}(2,132)=3.081, P=0.049]$. Post hoc tests on different designations revealed that $\mathrm{MD}(\mathrm{M}=3.67$, $\mathrm{SD}=0.69)$ confidence level was significantly different from SN $(\mathrm{M}=3.26, \mathrm{SD}=0.64)$ with $P=0.039$. However, the overall confidence level between MD and AMO showed no significant difference with $P=0.516$

Similarly, one-way ANOVA comparison of overall confidence level with LOS showed significant difference $[\mathrm{F}(2,132)=5.46, P=0.005]$. Post hoc test showed the confidence level of those with $\operatorname{LOS}<4$ years $(\mathrm{M}=3.24, \mathrm{SD}=0.61)$ was significantly different from those with LOS $4-10$ years $(\mathrm{M}=3.60, \mathrm{SD}=0.71)$ with $P=0.029$. A comparison between $\operatorname{LOS}<4$ years and LOS $>10$ years revealed significant mean differences $(\mathrm{M}=3.80, \mathrm{SD}=0.59)$ with $P=0.006$.

The mean score for ARC among the EHCW was 3.35 $(\mathrm{SD}=0.77)$ with no statistically significant difference $[(\mathrm{F} 2,132), 1.264, P=0.286]$ based on ANOVA. A confidence level score of 3.55 differentiates between high and low confidence groups (Table 3). Our results revealed all designations had low confidence in managing the airway. 
Table 1. Differences in Knowledge and Confidence Level of by Demographics $(\mathrm{N}=135)$

\begin{tabular}{|c|c|c|c|c|c|c|c|c|c|c|}
\hline Particulars & & $\begin{array}{l}\Xi \\
\Xi \\
\bar{D} \\
\Xi \\
\text { Z }\end{array}$ & $\%$ & $\begin{array}{l}0 \\
0 \\
0 \\
0 \\
0 \\
0 \\
0 \\
0 \\
0 \\
0 \\
0 \\
0 \\
0 \\
0\end{array}$ & 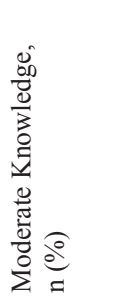 & $\begin{array}{l}0 \\
0 \\
0 \\
0 \\
0 \\
0 \\
0 \\
0 \\
0 \\
0 \\
0 \\
0 \\
0 \\
0 \\
0\end{array}$ & $X^{2}(\mathrm{P})$ & $\begin{array}{l}0 \\
0 \\
0 \\
0 \\
0 \\
0 \\
0 \\
0 \\
0 \\
0 \\
0 \\
0 \\
0\end{array}$ & 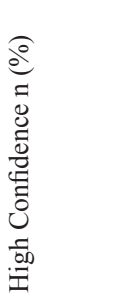 & $X^{2}(\mathrm{P})$ \\
\hline Overall & & 135 & 100 & $1(0.7)$ & $41(30.4)$ & $93(68.9)$ & & $63(46.7)$ & $72(53.3)$ & \\
\hline \multirow{3}{*}{ 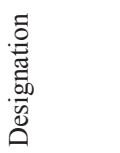 } & MD & 62 & 45.9 & $0(0.0)$ & $13(21.0)$ & $49(79.0)$ & 6.790 & $27(43.5)$ & $35(56.5)$ & 4.95 \\
\hline & AMO & 51 & 37.8 & $1(2.0)$ & $20(39.2)$ & $30(58.8)$ & $(0.147)$ & $21(41.2)$ & $30(58.8)$ & $(0.084)$ \\
\hline & SN & 22 & 16.3 & $0(0.0)$ & $8(36.4)$ & $14(63.6)$ & & $15(68.2)$ & $7(31.8)$ & \\
\hline 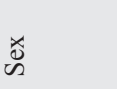 & Female & 70 & 51.9 & $0(0.0)$ & $19(27.1)$ & $51(72.9)$ & $(0.385)$ & $37(52.9)$ & $33(47.1)$ & $(0.135)$ \\
\hline \multirow{3}{*}{ 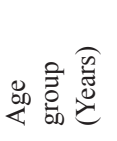 } & $20-30$ у.о & 37 & 27.4 & $1(2.7)$ & $18(48.6)$ & $18(48.6)$ & 12.10 & $25(67.6)$ & $12(32.4)$ & 8.95 \\
\hline & $31-40$ y.o & 90 & 68.2 & $0(0.0)$ & $20(22.2)$ & $70(77.8)$ & (0.017) & $35(38.9)$ & $55(61.1)$ & (0.011) \\
\hline & $41-50$ у.о & 8 & 4.4 & $0(0.0)$ & $3(37.5)$ & $5(62.5)$ & & $3(37.5)$ & $5(62.5)$ & \\
\hline \multirow{3}{*}{ 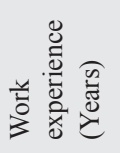 } & $<4 y$ & 33 & 24.4 & $0(0.0)$ & $18(54.5)$ & $15(45.5)$ & 12.689 & $22(66.7)$ & $11(33.3)$ & 7.613 \\
\hline & $4-10 y$ & 78 & 57.8 & $1(1.3)$ & $17(21.8)$ & $60(76.9)$ & $(0.013)$ & $33(42.3)$ & $45(57.7)$ & (0.022) \\
\hline & $>10 y$ & 24 & 17.8 & $0(0.0)$ & $6(25.0)$ & $18(75.0)$ & & $8(33.3)$ & $16(66.7)$ & \\
\hline \multirow{2}{*}{ 仓่ } & Present & 16 & 11.9 & $0(0.0)$ & $6(37.5)$ & $10(62.5)$ & 0.546 & $4(25)$ & $12(75)$ & 3.42 \\
\hline & Absent & 119 & 88.1 & $1(0.8)$ & $35(29.4)$ & $83(69.7)$ & $(0.761)$ & $59(49.6)$ & $60(50.4)$ & $(0.064)$ \\
\hline
\end{tabular}

$P<0.05$ was considered significant. Bold values show significant differences.

Total scores for knowledge ranged from $0-40$. A score of $<24$ was set for poor knowledge, $24-31$ for moderate, $\geq 32$ for good knowledge on resuscitation and airway management of COVID-19 patients.

Total scores for confidence level ranged from $0-5$. A mean score of $\geq 3.55$ was set for good confidence level, $<3.55$ set for low confidence level in resuscitation and airway management of COVID-19 patients.

$\mathrm{AMO}=$ Assistant Medical Officers; $\mathrm{MD}=$ Medical Doctors; $\mathrm{SN}=$ Staff Nurses

ANOVA analysis of ARC against LOS showed statistically significant difference $(\mathrm{F}(2,132)=9.143$, $P=0.000)$. Post hoc test showed the ARC for those with $\operatorname{LOS}<4$ years $(\mathrm{M}=2.89, \mathrm{SD}=0.72)$ was significantly different from those with LOS 4-10 years and $>10$ years $(\mathrm{M}=3.45, \mathrm{SD}=0.76)$ and $(\mathrm{M}=3.64, \mathrm{SD}$ $=0.61)$, respectively, with $P=0.001$. However, there was no statistically significant difference between the group of 4-10 years and those with $>10$ years of service.

An analysis of RRC against designation and LOS with one way ANOVA showed significant difference $[\mathrm{F}(2,132)$ $=4.655, P=0.011]$. Post hoc analysis showed significant difference between $\mathrm{MD}(\mathrm{M}=3.84, \mathrm{SD}=0.63)$ and $\mathrm{SN}$ $(\mathrm{M}=3.35, \mathrm{SD}=0.65)$, with $P=0.011$. However, this was not the case with LOS, $P=0.055$ (Table 3 ).
There was a significant association between overall confidence level and knowledge scores with $P=0.017$. In terms of confidence level, 72 respondents showed high, while 63 had low, confidence. Within the group with high confidence level, 79\% $(n=57)$ also possessed good knowledge. However, among those in the low confidence group, only $57 \%(n=36)$ of the respondents possessed good knowledge.

An analysis of individual attributes of confidence revealed a greater proportion of $\mathrm{EHCW}$ had high confidence level in PPE inspection [ $\mathrm{n}=107$ (79.3\%)], taking action on breached-PPE $[\mathrm{n}=103$ (76.3\%)] and performing high quality chest compression $[\mathrm{n}=82(60.1 \%)]$. Notably less than half of the EHCW were confident in either resuscitating, leading the 
Table 2. Knowledge of Airway and Resuscitation on COVID-19 Patients Among Different Professions (by designation) and Length of Service (LOS)

\begin{tabular}{|c|c|c|c|c|}
\hline \multicolumn{5}{|l|}{ Knowledge } \\
\hline \multirow[t]{6}{*}{ Profession } & & $\begin{array}{l}\text { Airway } \\
(/ 23)[\%]\end{array}$ & $\begin{array}{l}\text { Resuscitation } \\
(/ 17)[\%]\end{array}$ & $\begin{array}{l}\text { Overall Mean } \\
(/ 40)[\%]\end{array}$ \\
\hline & MD & $\begin{array}{l}20.67(\mathrm{SD} 1.99) \\
{[89.8]}\end{array}$ & $\begin{array}{l}13.21(\mathrm{SD} 1.79) \\
{[77.7]}\end{array}$ & $\begin{array}{l}33.88(\mathrm{SD} 3.09) \\
{[84.7]}\end{array}$ \\
\hline & $\mathrm{SN}$ & $\begin{array}{l}18.68(\mathrm{SD} 2.70) \\
{[81.2]}\end{array}$ & $\begin{array}{l}13.32(\mathrm{SD} 1.89) \\
{[78.3]}\end{array}$ & $\begin{array}{l}32.00(\mathrm{SD} 3.60) \\
{[80.0]}\end{array}$ \\
\hline & $\mathrm{AMO}$ & $\begin{array}{l}19.67(\mathrm{SD} 2.45) \\
{[85.5]}\end{array}$ & $\begin{array}{l}12.61(\mathrm{SD} 2.28) \\
{[74.1]}\end{array}$ & $\begin{array}{l}32.28(\mathrm{SD} 4.03) \\
{[80.7]}\end{array}$ \\
\hline & Total & $\begin{array}{l}19.96(\mathrm{SD} 2.39) \\
{[86.8]}\end{array}$ & $\begin{array}{l}13.00(\mathrm{SD} 2.01) \\
{[76.5]}\end{array}$ & $\begin{array}{l}32.96(\mathrm{SD} 3.63) \\
{[82.4]}\end{array}$ \\
\hline & ANOVA & $P=0.002$ & $P=0.207$ & $P=0.025$ \\
\hline \multirow[t]{6}{*}{ Length of service } & & & & Total \\
\hline & $<4 \mathrm{y}$ & $\begin{array}{l}18.82(\mathrm{SD} 2.35) \\
{[81.8]}\end{array}$ & $\begin{array}{l}12.39(\mathrm{SD} 1.68) \\
{[72.9]}\end{array}$ & $\begin{array}{l}31.21(\mathrm{SD} 3.19) \\
{[78.0]}\end{array}$ \\
\hline & $4-10 y$ & $\begin{array}{l}20.50(\text { SD 2.32) } \\
{[89.1]}\end{array}$ & $\begin{array}{l}13.21(\mathrm{SD} 1.97) \\
{[77.7]}\end{array}$ & $\begin{array}{l}33.71 \text { (SD 3.39) } \\
{[84.3]}\end{array}$ \\
\hline & $>10 y$ & $\begin{array}{l}19.79(\text { SD 2.17) } \\
{[86.1]}\end{array}$ & $\begin{array}{l}13.17(\text { SD 2.44) } \\
{[77.5]}\end{array}$ & $\begin{array}{l}32.96(\mathrm{SD} 4.21) \\
{[82.4]}\end{array}$ \\
\hline & Total & $\begin{array}{l}19.96 \text { (SD 2.39) } \\
{[86.8]}\end{array}$ & $\begin{array}{l}13.00(\text { SD 2.01) } \\
{[76.5]}\end{array}$ & $\begin{array}{l}32.96(\mathrm{SD} 3.62) \\
{[82.4]}\end{array}$ \\
\hline & ANOVA & $P=0.003$ & $P=0.137$ & $P=0.004$ \\
\hline
\end{tabular}

Level of significance $P<0.05$

Table 3. Levels of Confidence on Airway and Resuscitation of COVID-19 Patients Among Different Designations and Lengths of Service.

\begin{tabular}{|c|c|c|c|c|}
\hline \multicolumn{5}{|l|}{ Confidence } \\
\hline \multirow[t]{6}{*}{ Profession } & & Airway & Resuscitation & Av. Mean \\
\hline & $\mathrm{MD}$ & $3.41(\mathrm{SD} 0.84)$ & $3.84(\mathrm{SD} 0.63)$ & 3.67 (SD 0.69) \\
\hline & $\mathrm{SN}$ & $3.11(\mathrm{SD} 0.68)$ & $3.35(\mathrm{SD} 0.65)$ & $3.26(\mathrm{SD} 0.64)$ \\
\hline & AMO & 3.37 (SD 0.78) & $3.63(\mathrm{SD} 0.71)$ & $3.53(\mathrm{SD} 0.68)$ \\
\hline & Total & 3.35 (SD 0.77) & $3.68(\mathrm{SD} 0.68)$ & $3.55(\mathrm{SD} 0.69)$ \\
\hline & & $P=0.286$ & $P=0.011$ & $P=0.049$ \\
\hline \multicolumn{5}{|c|}{ Length of service } \\
\hline & $<4 \mathrm{y}$ & $2.89(\mathrm{SD} 0.72)$ & $3.48(\mathrm{SD} 0.60)$ & $3.24(\mathrm{SD} 0.61)$ \\
\hline & $4-10 y$ & 3.45 (SD 0.76) & 3.67 (SD 0.72) & $3.60(\mathrm{SD} 0.71)$ \\
\hline & Total & $3.35(\mathrm{SD} 0.77)$ & $3.68(\mathrm{SD} 0.68)$ & 3.55 (SD 0.69) \\
\hline & & $P=0.000$ & $P=0.055$ & $P=0.005$ \\
\hline
\end{tabular}

Level of significance $P<0.05$ 
resuscitation, managing the airway, or achieving first-attempt-intubation-success in management of COVID-19 patients (Table 4).

\section{Discussion}

This study, which was the first to be carried out among the EHCW in Malaysia during the initial period of the COVID-19 pandemic, revealed that the majority of our EHCW were knowledgeable but lacked confidence, especially in managing airway and handling resuscitation of suspected COVID-19 patients. Airway management poses a risk of aerosol generation with inadequate training, and may potentially jeopardise personnel safety and increase the spread of the disease. ${ }^{21}$ The overall knowledge of COVID-19 among EHCW was good. Our study had similar findings with those of Bhagavatula et $\mathrm{al}^{22}$, and Zhou et al. which showed that MD possess higher knowledge level than SN and paramedics, which directly influenced their attitudes and confidence levels. ${ }^{13}$ This may be related to the role of MD in resuscitation as team leader and the person who performs the intubation procedure. Nevertheless, these previous studies showed a significant majority $(>90 \%)$ of the respondents had good knowledge, whereas our findings only showed $68.9 \%$. This is possibly due to the scope of knowledge covered in our study, which focused on resuscitation and technicalities of airway management, as opposed to COVID-19 transmission in general. The findings are significant in the context of the current situation, as
EHCW knowledge is essential in reducing the risk of transmission during aerosol generating procedure (AGP) and safety during resuscitation in general.

As people working at the frontline, EHCW should be knowledgeable in the resuscitation of COVID-19 patients. Adequate knowledge is paramount as the disease is extremely dangerous and easily spreads through direct contact or respiratory secretions including during resuscitation. ${ }^{23}$ Previous studies have shown that the level of knowledge of HCW is related to the length of service. A study by Mohamad et al. on junior doctors showed that $68.3 \%$ did not have sufficient knowledge to perform resuscitation, including CPR. ${ }^{24}$ This is in line with our findings where junior EHCW of fewer than 4 years LOS had lower knowledge compared to their senior colleagues.

Our results also showed higher confidence level in airway management among the senior EHCW especially those with more than 10 years of working experience. This is probably due to their previous involvement in outbreaks such as SARS, H1N1, MERS-CoV and exposures to various level of difficulties of airway management. It is similar to a study done in Korea that found confidence level in managing the airway correlated with experience, and the rate of successful intubation was higher among senior physicians. ${ }^{25}$ Meanwhile, a local survey among junior MD supports our findings, which showed inadequate advanced airway and resuscitation exposure leading to lack of confidence in

Table 4. Confidence of EHCW Across Different Attributes of COVID-19 Patient Management

\begin{tabular}{|c|c|c|c|c|}
\hline No & Attributes & $\begin{array}{l}\text { Confident } \\
\text { (based on Likert scale } \\
4 \text { and5 } \\
(\mathrm{n}, \%)\end{array}$ & $\begin{array}{l}\text { Not Confident } \\
\text { (based on Likert } \\
\text { scale of 1-3) } \\
(\mathrm{n}, \%)\end{array}$ & Mean scores \\
\hline Q1 & Comfortable resuscitating a PUI patient & $50(37.0 \%)$ & $85(63.0 \%)$ & $3.24(\mathrm{SD}=0.87)$ \\
\hline Q2 & Well trained to manage the airway & $61(45.2 \%)$ & $74(54.8 \%)$ & $3.28(\mathrm{SD}=0.97)$ \\
\hline Q3 & Confident in managing the airway & $58(43 \%)$ & $77(57.0 \%)$ & $3.35(\mathrm{SD}=0.87)$ \\
\hline Q4 & Comfortable in doing High Quality Chest Compression & $82(60.1 \%)$ & $53(39.3 \%)$ & $3.66(\mathrm{SD}=0.94)$ \\
\hline Q5 & Confident to lead the resuscitation team & $47(34.8 \%)$ & $88(65.2 \%)$ & $3.11(\mathrm{SD}=1.03)$ \\
\hline Q6 & Confident to check for breached PPE & $107(79.3 \%)$ & $28(20.7 \%)$ & $4.14(\mathrm{SD}=0.86)$ \\
\hline Q7 & Comfortable in voicing concern to seniors & $91(67.4 \%)$ & $44(32.6 \%)$ & $3.87(\mathrm{SD}=0.91)$ \\
\hline Q8 & Confident successful intubation on $1^{\text {st }}$ attempt & $49(36.3 \%)$ & $86(63.7 \%)$ & $3.22(\mathrm{SD}=1.03)$ \\
\hline Q9 & Confidence on action to take if PPE breached during resuscitation & $103(76.3 \%)$ & $32(23.7 \%)$ & $4.07(\mathrm{SD}=0.89)$ \\
\hline Q10 & Comfortable in handling the patient's vomitus during intubation & $74(54.8 \%)$ & $61(45.2 \%)$ & $3.54(\mathrm{SD}=0.98)$ \\
\hline
\end{tabular}


patient management. ${ }^{26}$ Nevertheless, our study revealed no significant difference in confidence in airway management between MD, SN and AMO. Our findings support the current recommendations for COVID-19 airway management to be led by the most experienced provider. ${ }^{8}$

Most EHCW were comfortable with the correct usage of PPE and its appropriate level. This finding was similarly discovered in a Singaporean study done on Avian influenza pandemic preparedness. ${ }^{27}$ Houghton et al. reported that clear guidelines and training sessions were among the essential factors to increase adherence towards infection control and prevention. ${ }^{28}$ Knowledge and perception of disease transmission also promote compliance to PPE guidelines. ${ }^{13,29,30}$ In our practice, self-inspection and buddy-system are used to check for proper PPE application and ensure it is working in order.

The 3 confidence attributes that received the lowest scores were resuscitation of COVID-19 patients, success at first intubation attempt, and leading the resuscitation team. The confidence in managing airway and resuscitation depends on the clinical experience such as the number of cases encountered and the total airway procedures performed by the EHCW. ${ }^{31}$ Nevertheless, with the uniqueness of managing a COVID-19 patient's airway, it was not surprising that the EHCW demonstrated lower confidence levels in these aspects.

In the present study, a significant number of respondents showed high knowledge scores in resuscitation and airway management of COVID-19 patients, but had low levels of confidence. On the other hand, adequate knowledge was not always translated into confidence in patient management. Adequate training and experience, ${ }^{32,33}$ perception of the disease, ${ }^{22}$ comorbidities, social stigma are possible confounding factors which may influence the level of confidence of the HCW. One of the contributing factors to the reduction in confidence among EHCW was the exponential rise in the number of COVID-19 cases and widespread dissemination of this news.

\section{Limitations and Recommendations}

This study has several limitations. It was a singlecentre study with a relatively small sample size involving the EHCW working in the ED. The majority of the respondents were doctors which limited its generalisation for the emergency workforce, which consists predominantly of nurses. As this study was designed to focus on determining the knowledge and confidence level of $\mathrm{EHCW}$, the competency level through psychomotor assessment and the associations of these factors with patients' outcome were not explored. To the best of our knowledge, currently, there is no published local data on this subject, hence the inability to compare with other facilities with similar settings.

Future multicentre studies with equally distributed designations among EHCW respondents are recommended to address these limitations. The association between knowledge, confidence and competence level with patients' outcome should also be the main focus for subsequent studies. Therefore, based on the findings from this study, we recommend that specialised training on airway management and resuscitation for suspected COVID-19 patients be conducted regularly for EHCW to improve their confidence and, hence, their readiness to face this pandemic.

\section{Conclusions}

EHCW shows good knowledge of airway management and resuscitation of suspected COVID-19 patients differs between different designations and LOS. In addition, the confidence level correlates positively with LOS. Although generally, the confidence level of EHCW was good, airway management, leading resuscitation and success of first attempt intubation for suspected COVID-19 patients were identified as areas for improvement. Future studies should explore this idiosyncrasy.

\section{Acknowledgements}

The authors would like to thank Pn Saadah Ahmad from the Research Unit Department of Emergency Medicine, UKM for her invaluable statistical input in this study and also the Department of Emergency Medicine, Hospital Canselor Tuanku Muhriz, for allowing us to conduct this study.

\section{REFERENCES}

1. Worldometers. Worldometer. COVID-19 Coronavirus pandemic. : Worldometer; 2020 [cited 2020 4thAugust 2020]. Available from: https:// www.worldometers.info/coronavirus/.

2. Baud D, Qi X, Nielsen-Saines K, Musso D, Pomar L, Favre G. Real estimates of mortality following COVID-19 infection. Lancet Infect Dis. 2020 Jul;20(7):773.

3. Mizumoto K, Chowell G. Estimating the risk of 2019 novel coronavirus death during the course of the outbreak in China, 2020. medRxiv. 2020.

4. Hannah Ritchie, Esteban Ortiz-Ospina, Diana Beltekian, Edouard Mathieu, Joe Hasell, Bobbie Macdonald, et al. Statistics and Research: Coronavirus (COVID-19) Deaths University of Oxford: University of Oxford; 2020 [cited 4 August 2020]. Available from: https://ourworldindata.org/coviddeaths.

5. Huang C, Wang Y, Li X, Ren L, Zhao J, Hu Y, et al. Clinical features of patients infected with 2019 novel coronavirus in Wuhan, China. The Lancet. 2020 Feb 15;395(10223):497-506. 
6. Hsu LY, Chia PY, Lim JF. The Novel Coronavirus (SARS-CoV-2) Pandemic. Ann Acad Med Singap. 2020 Mar 16;49(3):105-7.

7. Goh KJ, Choong MC, Cheong EH, Kalimuddin S, Duu Wen S, Phua GC, et al. Rapid Progression to Acute Respiratory Distress Syndrome: Review of Current Understanding of Critical Illness from COVID-19 Infection. Ann Acad Med Singap. 2020 March 16;49(3):108-18

8. Brewster DJ, Chrimes NC, Do TB, Fraser K, Groombridge CJ, Higgs A, et al. Consensus statement: Safe Airway Society principles of airway management and tracheal intubation specific to the COVID-19 adult patient group. Med J Aust. 2020 Jun; 212(10):472-481.

9. Mohd Hisham I, Azlan Helmy AS, Ismail MS. The Preparation, Delivery and Outcome of COVID-19 Pandemic Training Program among the Emergency Healthcare Frontliners (EHFs): The Malaysian Teaching Hospital Experience. Medicine and Health 2020; 15(1):250-65.

10. Wang J, Zhou M, Liu F. Exploring the reasons for healthcare workers infected with novel coronavirus disease 2019 (COVID-19) in China. J Hosp Infect. 2020 May;105(1):100-1.

11. Ho CS, Chee CY, Ho RC. Mental health strategies to combat the psychological impact of COVID-19 beyond paranoia and panic. Ann Acad Med Singap. 2020 Mar 16;49(1):155-160.

12. Saqlain M, Munir MM, Ur Rehman S, Gulzar A, Naz S, Ahmed Z, et al. Knowledge, attitude, practice and perceived barriers among healthcare professionals regarding COVID-19: A Cross-sectional survey from Pakistan. J Hosp Infect 2020 Jul;105(3):419-23.

13. Zhou M, Tang F, Wang Y, Nie H, Zhang L, You G, et al. Knowledge, attitude and practice regarding COVID-19 among health care workers in Henan, China. J Hosp Infect. 2020 Jun;105 (2):183-87.

14. DrNoor Hisham Abdullah. Kenyataan Akhbar Ketua Pengarah Kesihatan Malaysia pada 24 Januari 2020-Tindakan KKMBagi PengesananKontak kepada Kes Pertama Positif Novel Coronavirus di negara Singapura pada 24 Januari 2020 Kuala Lumpur: Ministry of Health Malaysia; 2020.

15. DrNoor HishamAbdullah. Kenyataan Akhbar Ketua Pengarah Kesihatan Malaysia pada 25 Januari 2020- Pengesanan Kes Baharu yang disahkan dijangkiti 2019 Novel Coronavirus (2019-nCoV) di Malaysia Kuala Lumpur: Ministry of Health Malaysia; 25 Januari 2020.

16. Shah AUM, Safri SNA, Thevadas R, Noordin NK, Abd Rahman A, Sekawi Z, et al. COVID-19 Outbreak in Malaysia: Actions Taken by the Malaysian Government. Int J Infect Dis. 2020 Aug;97:108-116.

17. Ministry of health Malaysia. Latest Update on COVID-19 in Malaysia: Ministry of health Malaysia; 2020 [cited 20206 August 2020]. Available from: http://covid-19.moh.gov.my/terkini.

18. Academy of Emergency Sciences Manila. AHA COVID 19 PALS Algorithm 2020 [update 9 April 2020; cited 10 June 2020]. Available from: https:/www.facebook.com/aesciencesmanila/posts/covid-bluecpr-in-the-time-of-covid-19-last-edited-april-10-2020-whats-new 1adde/839713119771071/)

19. Edelson DP, Sasson C, Chan PS, Atkins DL, Aziz K, Becker LB, et al. Interim Guidance for Basic and Advanced Life Support in Adults, Children, and Neonates With Suspected or Confirmed COVID-19: From the Emergency Cardiovascular Care Committee and Get With the Guidelines ${ }^{\circledR}$-Resuscitation Adult and Pediatric Task Forces of the American Heart Association in Collaboration with the American Academy of Pediatrics, American Association for Respiratory Care, American College of Emergency Physicians, The Society of Critical Care Anesthesiologists, and American Society of Anesthesiologists: Supporting Organizations: American Association of Critical Care Nurses and National EMS Physicians. Circulation. 23 June 2020;141(25):e933-e943.
20. Saiboon IM, Apoo FN, Jamal SM, Bakar AA, Yatim FM, Jaafar JM, et al. Improving the position of resuscitation team leader with simulation (IMPORTS); a pilot cross-sectional randomized intervention study. Medicine (Baltimore). 2019 Dec;98(49):e18201.

21. Raboud J, Shigayeva A, McGeer A, Bontovics E, Chapman M, Gravel $D$, et al. Risk factors for SARS transmission from patients requiring intubation: a multicentre investigation in Toronto, Canada. PLoS One. 2010 May 19;5(5)

22. Bhagavathula AS, Aldhaleei WA, Rahmani J, Mahabadi MA, Bandari DK. Novel coronavirus (COVID-19) knowledge and perceptions: a survey on healthcare workers. JMIR Public Health Surveill. 2020 Apr 30;6(2):e19160.

23. Nolan J, Monsieurs K, Bossaert L, Böttiger B, Greif R, Lott C, et al. European Resuscitation Council COVID-19 Guidelines Executive Summary. Resuscitation. 2020 Aug;153:45-55.

24. Mohammed Z, Arafa A, Saleh Y, Dardir M, Taha A, Shaban H, et al. Knowledge of and attitudes towards cardiopulmonary resuscitation among junior doctors and medical students in Upper Egypt: cross-sectional study. Int J Emerg Med. 2020 Apr 22;13(1):19.

25. Kim C, Kang HG, Lim TH, Choi BY, Shin Y-j, Choi HJ. What factors affect the success rate of the first attempt at endotracheal intubation in emergency departments? Emerg Med J. 2013 Nov;30(11):888-92.

26. Chew K, Hashairi FM, Zarina ZI, Farid AS, Yazid MA, Hisamudddin $\mathrm{N}$. A survey on the knowledge, attitude and confidence level of adult cardiopulmonary resuscitation among junior doctors in Hospital Universiti Sains Malaysia and Hospital Raja Perempuan Zainab II, Kota Bharu, Kelantan, Malaysia. Med J Malaysia. 2011 Mar;66(1):56-9.

27. Wong TY, Koh GC, Cheong SK, Lee HY, Fong YT, Sundram M, et al. Concerns, perceived impact and preparedness in an avian influenza pandemic--a comparative study between healthcare workers in primary and tertiary care. Ann Acad Med Singap. 2008 Feb;37(2):96.

28. Houghton C, Meskell P, Delaney H, Smalle M, Glenton C, Booth A, et al. Barriers and facilitators to healthcare workers' adherence with infection prevention and control (IPC) guidelines for respiratory infectious diseases: a rapid qualitative evidence synthesis. Cochrane Database Syst Rev. 2020 Apr 21;4(4):CD013582.

29. Barati M, Bashirian S, Jenabi E, Khazaei S, Karimi-Shahanjarini A, Zareian S, et al. Factors Associated with Preventive Behaviours of COVID-19 among Hospital Staff in Iran in 2020: An Application of the Protection Motivation Theory. J Hosp Infect. 2020 Jul;105(3):430-433.

30. Shi Y, Wang J, Yang Y, Wang Z, Wang G, Hashimoto K, et al. Knowledge and attitudes of medical staff in Chinese psychiatric hospitals regarding COVID-19. Brain Behav Immun Health. 2020 Apr;4:100064.

31. Awad Z, Pothier D. Management of surgical airway emergencies by junior ENT staff: a telephone survey. J Laryngol Otol. 2007 Jan;121(1):57-60.

32. Mark ME, LoSavio P, Husain I, Papagiannopoulos P, Batra PS, Tajudeen BA. Effect of Implementing Simulation Education on Health Care Worker Comfort With Nasopharyngeal Swabbing for COVID-19. Otolaryngol Head Neck Surg. 2020 Aug; 163(2):271-274. doi: 10.1177/0194599820933168.

33. Mouli TC, DavuluriA, Vijaya S, PriyankaADY, Mishra SK. Effectiveness of simulation based teaching of ventilatory management among non-anaesthesiology residents to manage COVID 19 pandemic-A Quasi experimental cross sectional pilot study. Indian J Anaesth. 2020 May;64(Suppl 2):S136-S140. doi: 10.4103/ija.IJA_452_20. Epub 23 May 2020. 